\title{
纳米金属氧化物催化含氮杂环类化合物的合成研究进展
}

\author{
张 金刘佳 马养民* 程 佩
}

(陕西科技大学化学与化工学院 教育部轻化工助剂化学与技术重点实验室 西安 710021)

\begin{abstract}
摘要 氮杂环化合物是杂环化合物的重要组成部分. 作为许多具有生理活性的生物碱、医药化合物的基本骨架，含氮 的杂环化合物的合成有巨大的应用价值. 近年来, 纳米金属氧化物作为一种绿色非均相的催化剂在氮杂环的构成方面 有越来越广泛的应用, 综述了近五年来纳米金属氧化物在催化含氮杂环化合物合成研究的新进展.

关键词 纳米氧化物; 含氮杂环化合物; 催化剂
\end{abstract}

\section{Progress in the Synthesis of N-Fused Heterocycles Catalyzed by Nanocrystalline Metal Oxides}

\author{
Zhang, Jin Liu, Jia Ma, Yangmin* Cheng, Pei \\ (Key Laboratory of Auxiliary Chemistry \& Technology for Chemical Industry, College of Chemistry \& Chemical Engineering, \\ Shaanxi University of Science \& Technology, Ministry of Education, Xi'an 710021)
}

\begin{abstract}
N$-Fused heterocycles are an important class of organic compounds. As a basic scaffold of a wide variety of biologically active alkaloids and synthetic pharmaceuticals and agrochemicals, the construction methods of $N$-fused heterocycles have attracted much attention. Significant efforts have been devoted to the application of the nanocrystalline metal oxides as heterogeneous, efficient and environmentally friendly catalyst in organic reaction. This review provides a summary of the synthesis of the different kinds of $N$-fused heterocycles in recent 5 years catalyzed by the nanocrystalline metal oxides.

Keywords nanocrystalline metal oxides; $N$-fused heterocycles; catalyst
\end{abstract}

含氮的杂环化合物是有机化合物的重要组成部分, 多数药物、维生素、天然产物、生物大分子等杂环均具 有含氮杂环的结构 ${ }^{[1]}$, 如喹啉、吡啶、吡咯、咔啉是天 然产物和药物分子的重要骨架, 生物 DNA 中碱基对嘌 呤、嘧啶氮杂环等. 含氮的杂环化合物广泛应用于合成 工业的医药活性结构和中间体，合成过程的保护基团， 手性助剂, 有机催化剂, 有机金属配体中. 在生物医学 和农业科学有大量的文献报道 ${ }^{[2]}$, 如在抑菌 ${ }^{[3]}$ 、抗炎 ${ }^{[4]}$ 、 抗肿瘤 ${ }^{[3]}$ 、抗抑郁 ${ }^{[6]}$ 、抗症疾 ${ }^{[7]}$ 等有广泛的应用, 同时在 农业科学中亦可用作农药, 如除草剂 ${ }^{[8]}$ 、杀虫剂等, 还可 以作为染料 ${ }^{[9]}$ 、苂光剂 ${ }^{[10]}$ 、分析检测试剂的主要骨架在 材料科学方面有重要应用, 在信息存储、塑料工业也有 巨大的应用前景. 因此含氮杂环的构建成为研究的热 点 ${ }^{[11 ~ 13]}$, 本文旨在从催化剂的角度对含氮杂环的合成
进行综述.

从廉价易得的原料出发, 探索一种绿色、温和、高 效的催化方法是合成含氮杂环化合物方法中的重点研 究方向, 每年有大量的关于这类化合物的合成新方法报 道. 其中, 非均相纳米金属氧化物催化剂在催化有机反 应中的应用被大大拓展，2014 年，吴否、范青华等 ${ }^{[14]}$ 的 综述中提到了纳米金属氧化物在不对称氢化和氢转移 反应中的研究进展, 这种纳米粒子本身可以作为催化活 性的位点, 还可以作为催化剂的载体, 进一步手性修饰 后可以应用于不对称氢化的合成反应. 2010 年以来, 纳 米粒子因具有易分离、可回收、催化效率高等优点而得 到快速发展, 不断有新型纳米金属氧化物被应用在温和 条件下高效催化合成杂环化合物 ${ }^{[15]}$. 这类催化剂具有 特殊的纳米尺寸, 能在反应物、溶剂中更好地分散; 具

* Corresponding author. E-mail: mym63@sina.com

Received September 6, 2016; revised November 27, 2016; published online December 12, 2016.

Project supported by the Natural Science Basic Research Plan in Shaanxi Province (No. 2014JQ2064), the Scientific Research Project Item for Key Laboratory of Shaanxi Provincal Education Department (No. 15JS012), and the Foundation for Young Scholars of Shaanxi University of Science \& Technology (No. BJ12-26).

陕西省自然科学基础研究计划(No. 2014JQ2064)、陕西省教育厅重点实验室项目(No. 15JS012)、陕西科技大学博士科研启动基金(No. BJ12-26)资助项 目. 
有大的比表面积, 从而大大地增加了催化活性和反应速 率; 反应条件更绿色环保, 高产率得到目标化合物; 反 应结束时, 催化剂及产物后处理简单, 催化剂稳定性高, 回收重复使用催化活性没有明显改变. 纳米金属氧化物 粒子在催化杂环形成过程中不但可以作为催化剂催化 反应，同时还可以作为其他贵重金属催化剂的载体, 使 成本高的催化剂更易分离且回收使用.

按照合成的含氮杂环目标化合物的类别, 本文对近 年来报道的纳米金属氧化物作为催化剂催化的含氮杂 环的合成方法及机理做了综述.

\section{1 纳米金属氧化物催化单环含氮杂环类化合物 合成}

\section{1 纳米金属氧化物催化含 1 个氮原子杂环化合物合} 成

\subsection{1 吡咯类化合物的合成}

纳米金属氧化物可以用于催化经典的反应制备吡 咯类化合物. 2012 年, Teimouri 等 ${ }^{[16]}$ 利用硫酸化的纳米 氧化锆为催化剂, 催化 2,5 -二羰基化合物与芳香胺在乙 醇中回流一锅法进行 Paal-Knorr 反应, 取得较高的产率. 2013 年, Zhang 课题组 ${ }^{[17]}$ 报道了一种简洁的方法, 制备
出具有磁性的纳米粒子负载的锑盐离子液体 $\left(\mathrm{Fe}_{2} \mathrm{O}_{3} @\right.$ $\mathrm{SiO}_{2}$-Sb-IL)催化剂, 通过 Clauson-Kaas 反应利用 2,5-二 烷氧基四氢呋喃和伯胺出发合成取代吡咯类化合物. 这 类催化剂呈现出良好的催化活性, 可以重复使用至少 6 次，反应在以水为溶剂的条件下进行. 第二年，其课题 组设计出两种不同的纳米氧化物负载的催化剂, 磁性纳 米 $\mathrm{CoFe}_{2} \mathrm{O}_{4}$ 负载的锑盐离子液体 $\left(\left[\mathrm{CoFe}_{2} \mathrm{O}_{4} @ \mathrm{SiO}_{2}\right.\right.$ DABCO-Sb] $)^{[18]}$ 和 $\mathrm{CoFe}_{2} \mathrm{O}_{4}$ 负载的钼催化剂 $\left(\left[\mathrm{CoFe}_{2} \mathrm{O}_{4} @\right.\right.$ $\left.\left.\mathrm{SiO}_{2}-\mathrm{PrNH}_{2}-\mathrm{Mo}(\mathrm{acac})_{2}\right]\right)^{[19]}$, 分别催化三组分芳香胺、硝 基烯类化合物及 1,3-二羰基化合物和四组分芳香醛、芳 香胺、1,3-二羰基化合物和硝基甲烷一锅法合成多取代 吡咯化合物(Scheme 1). 这类磁性的非均相催化剂可以 通过其他磁性物质吸出回收利用而不损失其催化活性, 在工业上有很大的应用前景.

2014 年, Sabbaghan 等 ${ }^{[20]}$ 报道了用纳米 $\mathrm{ZnO}$ 为催化 剂, 催化脂肪胺、不同取代的溴代苯乙酮与二乙炔酯三 组分在温和条件下高效合成多取代的吡咯类化合物, 并 且反应不需要溶剂参与, 更加绿色环保 (Scheme 1). 同 时还研究了不同的纳米结构的催化剂对催化活性的影 响, 结果发现当催化剂纳米 $\mathrm{ZnO}$ 为棒状结构时, 产物产 率最高. 催化的机理研究表明, 纳米 $\mathrm{ZnO}$ 粒子催化反应

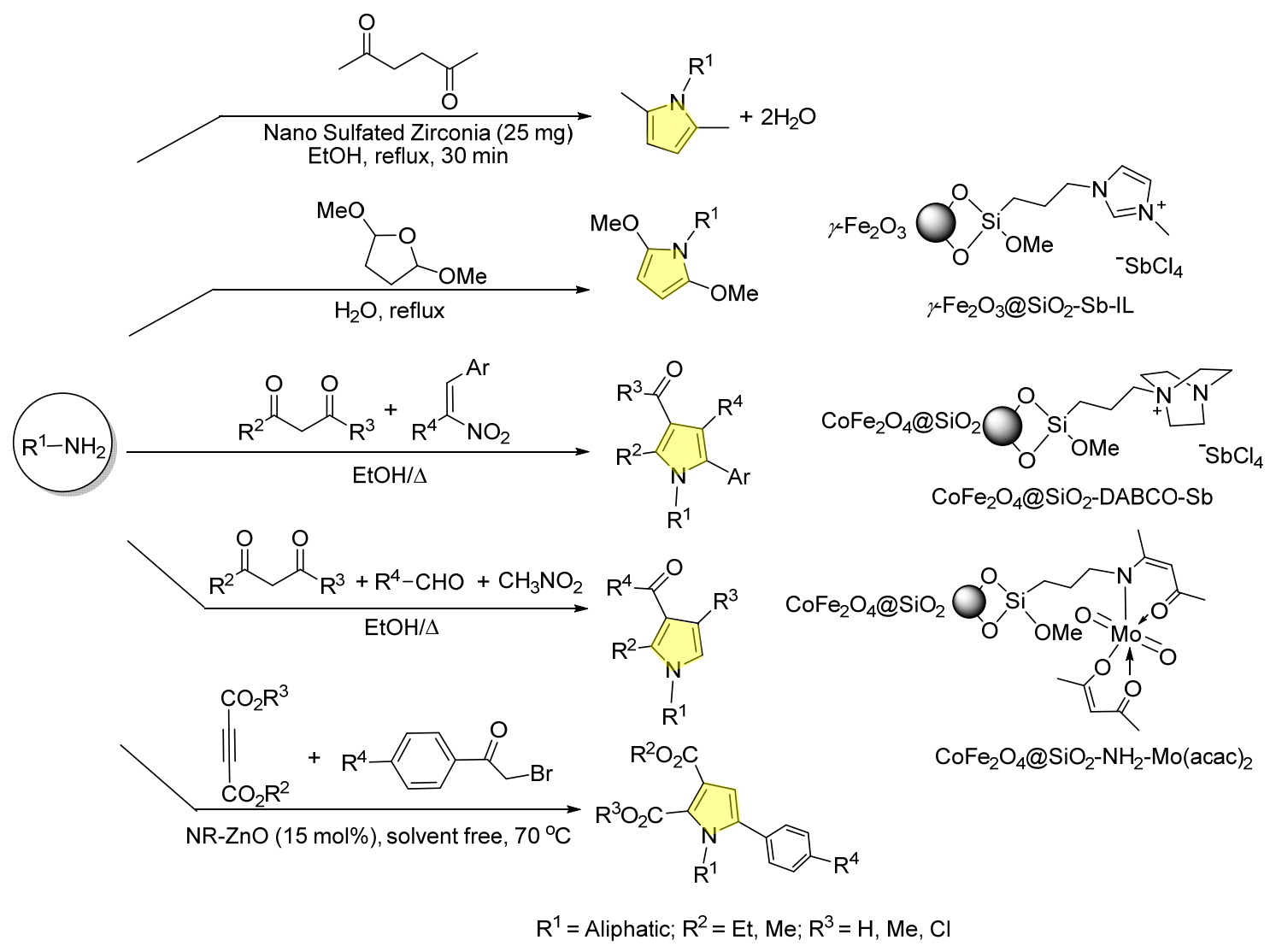

图式 $1 N$-取代吡咯类化合物合成

Scheme 1 Synthesis of $N$-substituted pyrroles 
可以视为路易斯酸 $\left(\mathrm{Zn}^{2+}\right)$ 及路易斯碱 $\left(\mathrm{O}^{2-}\right)$ 共同作用, $\mathrm{Zn}^{2+}$ 与丁炔二甲酯的酯基作用, $\mathrm{O}^{2-}$ 与苯甲酰基相互作 用, 从而与氨基成环形成吡咯骨架, 机理如 Scheme 2 所 示.

\section{1 .2 噻唑类化合物的合成}

噻唑类化合物是一类重要的含氮和硫的五元杂环 化合物, 在农业生产中有广泛的应用, 例如已经商品化 的农药土菌灵、噻唑菌胺等, 这类化合物的合成被学者 广泛关注. Hajinasiri 等 ${ }^{[21]}$ 以脂肪胺、异硫氰酸酯、溴代 羰基化合物为原料, 在室温无溶剂条件下, 利用实验室 制备的纳米 $\mathrm{ZnO}$ 为催化剂催化多组分合成 1,3-噻唑类衍 生物(Eq. 1), 取得较高产率, 并且催化剂形貌用扫描电 子显微镜(SEM)表征也呈现棒状结构, 并对反应机理进 行了探索. 推测纳米 $\mathrm{ZnO}$ 棒状结构上具有路易斯酸和 路易斯碱作用位点催化反应的进行.

Mokhtary 等 ${ }^{[22]}$ 利用离子液体和纳米 $\mathrm{Fe}_{3} \mathrm{O}_{4}$ 负载的
$\mathrm{SiO}_{2}$ 催化剂(MNPs@ $\mathrm{SiO}_{2}$-IL)在无溶剂条件下三组分合 成了噻唑酮类化合物, 反应原料为芳香醛、芳香胺及統 基乙酸(Scheme 3). 反应推测离子液体甲基咪唑阳离子 在催化过程中与芳香醛羰基结合, 增加了羰基的亲电 性，加快了亚胺中间体的形成.

\subsection{3 吡啶类化合物的合成}

2013 年, Sobhani 等 ${ }^{[23]}$ 将离子液体乙二胺磺酸盐固 定在纳米 $\gamma-\mathrm{Fe}_{2} \mathrm{O}_{3}$ 粒子上 $\left(\gamma-\mathrm{Fe}_{2} \mathrm{O}_{3}-2-\mathrm{HEAS}\right)$ 作为一种非 均相催化剂用于一锅法合成多取代吡啶的衍生物中. 反 应原料为芳香醛、丙二腈、硫酚类化合物(Eq. 2), 在催 化剂的作用下反应不需要溶剂参与, 反应时间短, 只需 要 $10 \mathrm{~min}$. 并且催化剂可以重复使用多次, 环境污染小.

2015 年, Eshghi 等 ${ }^{[24]}$ 设计了一种磁性的纳米材料, 用于三组分合成四氢吡啶类化合物(Eq. 3), 催化反应在 温和的条件下进行并取得较高产率. 反应完成后, 催化 剂易分离, 大大减小了后处理的步骤, 使反应更加简洁.
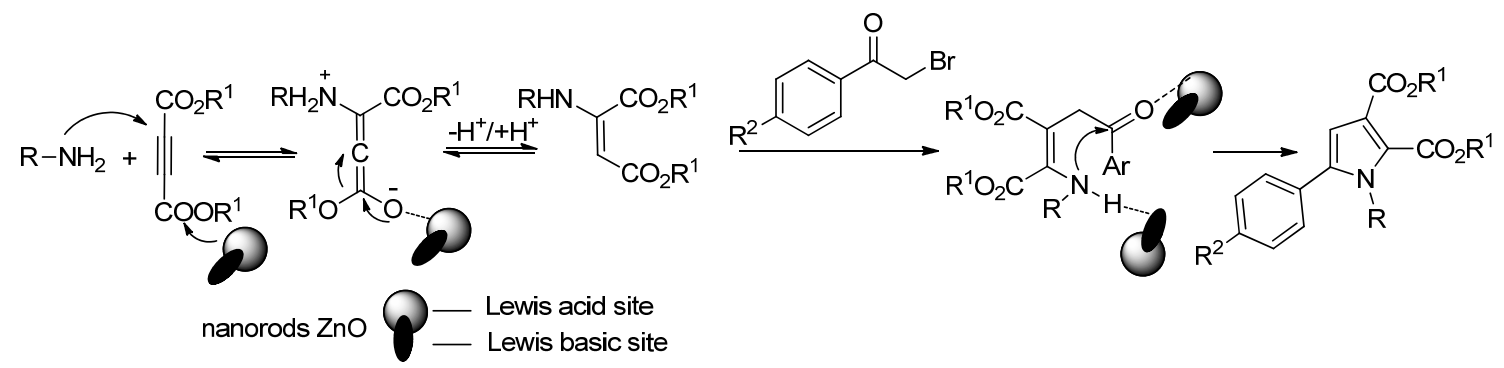

图式 2 纳米氧化锌催化生成吡咯类化合物机理图

Scheme 2 Possible mechanism for the formation of substituted pyrroles catalyzed by $\mathrm{ZnO}$ nanorods
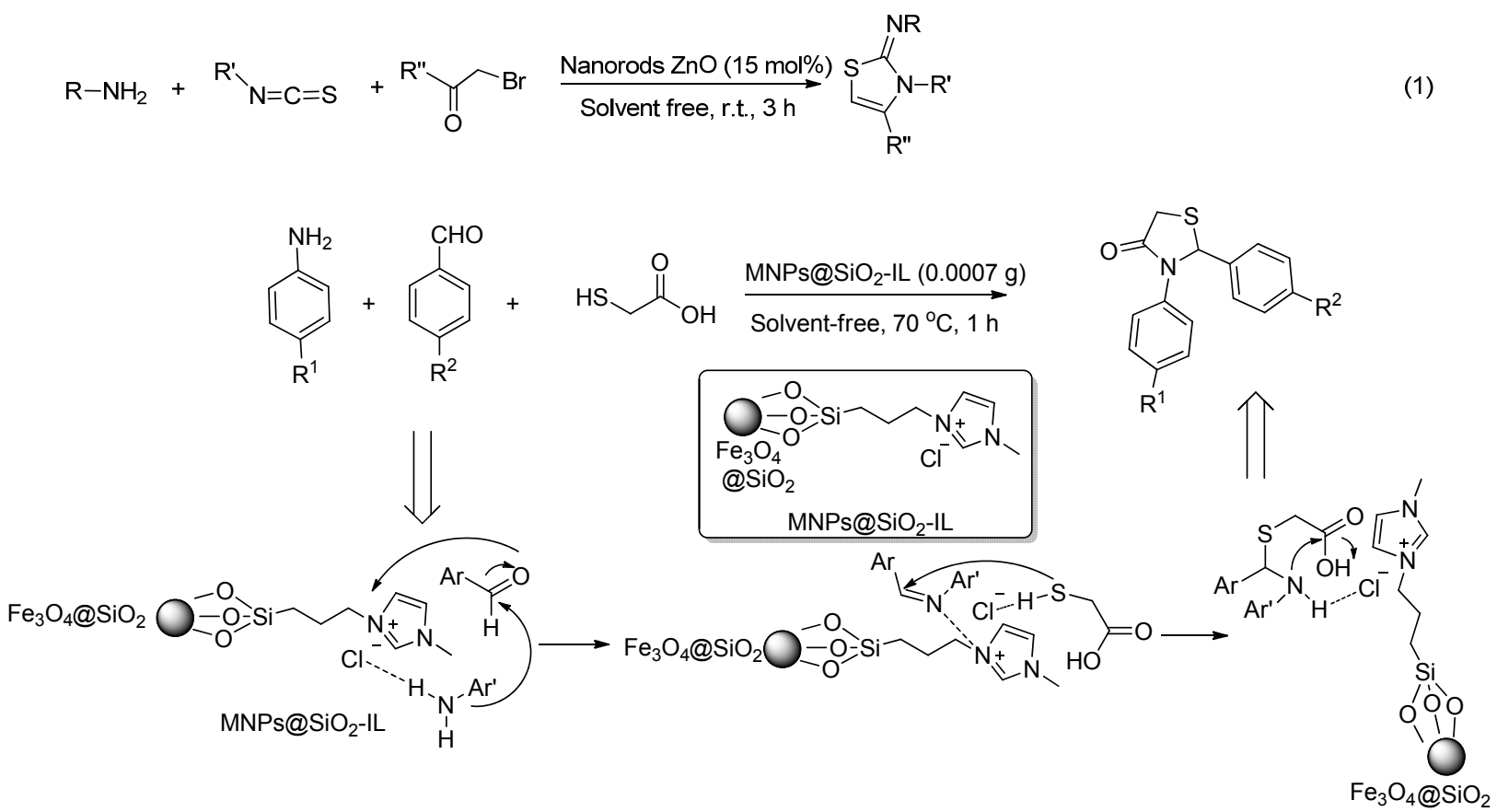

图式 $3 \mathrm{MNPs} @ \mathrm{SiO}_{2}$-IL 催化合成噻唑类化合物机理图

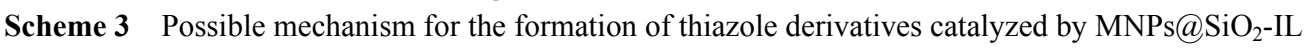




$$
\text { (1) }
$$

\section{2 纳米金属氧化物催化含 2 个氮原子杂环化合物合} 成

\subsection{1 咪唑类杂环化合物的合成}

咪唑类化合物因其重要的药用价值受到广泛关注. 有许多文献报道纳米粒子催化下 2,4,5-三取代咪唑类化 合物的合成. 其中以二苯基乙二酮、脂肪醛或芳香醛、 乙酸铵为原料的合成路线研究比较广泛. 报道过的纳米 粒子催化剂有: 硫酸化的纳米氧化锆 $(\mathbf{A})$ 催化剂 ${ }^{[25]}$, 这 类催化剂催化条件温和, 以乙醇为溶剂, 环境污染小, 原料中吸电子基团和供电子基团对产率没有影响. 氨基 磺酸改性的磁性纳米 $\mathrm{Fe}_{3} \mathrm{O}_{4}$ 粒子 $\left(\mathrm{Fe}_{3} \mathrm{O}_{4}-\mathrm{MNPs}, \mathbf{B}\right)$ 催化 剂 $^{[26]}$, 反应过程不需要溶剂参与, 微波辅助下大大减少 了常规加热时所需要的时间，产率均在 $93 \%$ 以上. 反应 结束时, 催化剂可以回收使用, 催化活性没有明显变化. 纳米 $\mathrm{Fe}_{3} \mathrm{O}_{4}$ 负载壳聚糖 $(\mathbf{C})$ 催化剂 ${ }^{[27]}$, 其合成中利用共沉 淀法将 $\mathrm{Fe}^{2+}$ 和 $\mathrm{Fe}^{3+}$ 负载在壳聚糖上, 使反应更加绿色环 保(Eq. 4). 在纳米催化剂催化下, 以二苯基乙二酮、有机 胺类、乙酸铵和一系列芳香醛四组分一锅法合成 $1,2,4,5-$ 四取代咪唑的方法也有广泛报道. 所用的纳米催化剂 有: 前文提到的硫酸化的纳米氧化锆(D)催化剂 ${ }^{[25]}$, 同 样可以应用到 $1,2,4,5$-四取代咪唑的合成, 反应条件温 和. 纳米 $\mathrm{Al}_{2} \mathrm{O}_{3}$ 粒子 $(\mathbf{E})$ 催化剂 ${ }^{[28]}$, 在紫外光照下, 乙醇 中回流反应，反应时间只有 $25 \mathrm{~min}$ (Eq. 4).

2013 年, Majee 等 ${ }^{[29]}$ 采用纳米 $\mathrm{In}_{2} \mathrm{O}_{3}$ 催化剂, 高产率 地合成了不对称取代的 $1 H$-咪唑. 反应原料为脒类化合 物和不同取代基的硝基烯烃, 推测其机理为 $\mathrm{In}^{3+}$ 催化脒 类化合物和硝基烯进行 Michael 加成反应(Scheme 4).

\subsection{2 吡唑类杂环化合物的合成}

2015 年, Zakerinasab 等 ${ }^{[30]}$ 设计了一种核壳结构的 $\mathrm{Fe}_{3} \mathrm{O}_{4}$ 负载的 $\mathrm{SiO}_{2}$ 纳米颗粒 $\mathrm{Fe}_{3} \mathrm{O}_{4} @ \mathrm{SiO}_{2} @$ PDETSA 用于

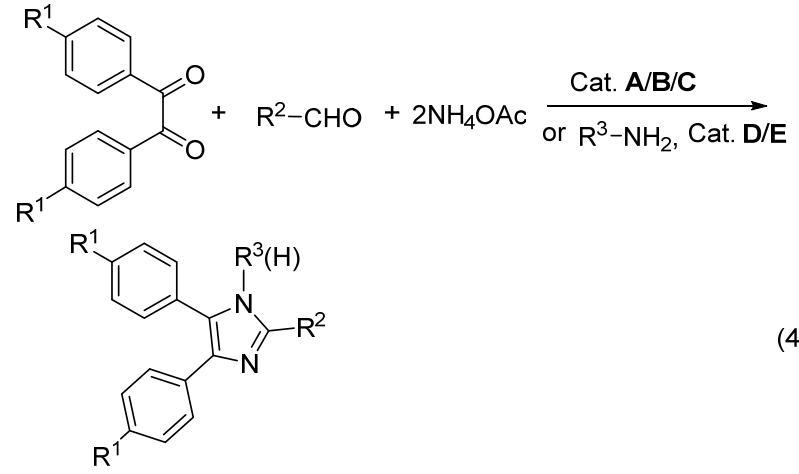

Cat. A: sulfated zirconia NPs (25 mg), EtOH, reflux, $75 \mathrm{~min}$ Cat. B: sulfated $\mathrm{Fe}_{3} \mathrm{O}_{4}-\mathrm{MNPs}(1.2 \mathrm{~mol} \%), \mathrm{MW}, 10 \mathrm{~min}$ Cat. C: Chitosan-coated $\mathrm{Fe}_{3} \mathrm{O}_{4} \mathrm{NPs}(0.05 \mathrm{~g})$, EtOH, reflux, $2 \mathrm{~h}$ Cat. D: sulfated zirconia NPs (25 mg), EtOH, reflux, $75 \mathrm{~min}$ Cat. E: $\mathrm{Al}_{2} \mathrm{O}_{3} \mathrm{NPs}(20 \mathrm{~mol} \%), \mathrm{EtOH}$, reflux, $25 \mathrm{~min}$

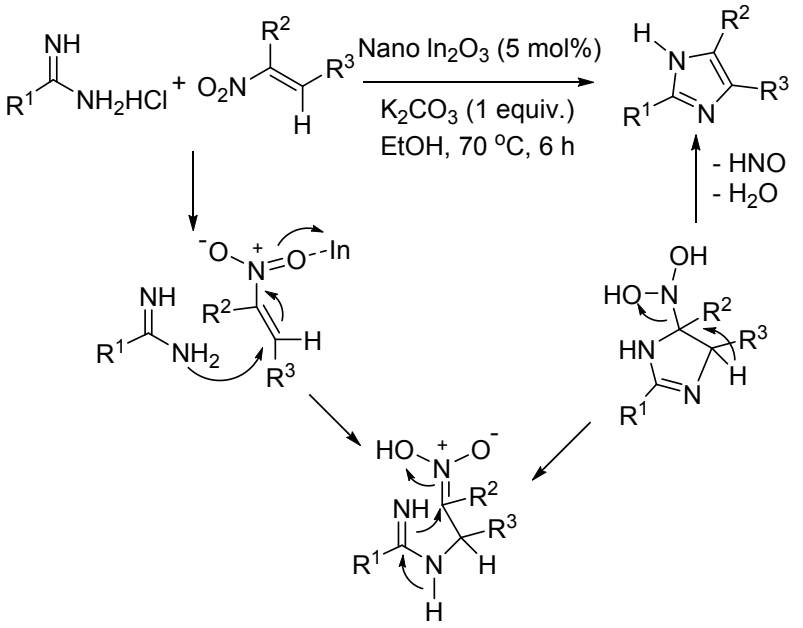

图式 4 纳米 $\mathrm{In}_{2} \mathrm{O}_{3}$ 催化咪唑类化合物合成机理

Scheme 4 The possible mechanism for the formation of substituted imidazoles catalyzed by $\operatorname{In}_{2} \mathrm{O}_{3} \mathrm{NPs}$

吡唑类衍生物的合成中，以 $\alpha, \beta$-二羰基化合物和肼或酰 肼衍生物为原料, 在室温条件下以水为溶剂反应，条件 
更加绿色温和, 高产率地得到目标化合物. 并且催化剂 用量少，可回收重复利用(Eq. 5).

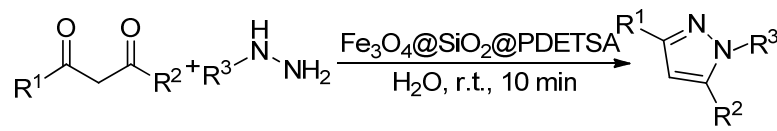

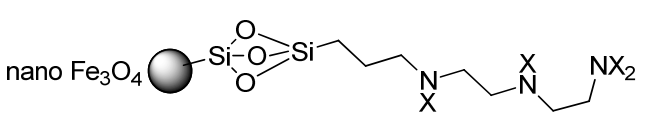

$\mathrm{Fe}_{3} \mathrm{O}_{4} @ \mathrm{SiO}_{2} @ P D E T S A$

\subsection{3 噁二唑类杂环化合物的合成}

2013 年, Sangshetti 等 ${ }^{[31]}$ 发明了一种合成 4,5,6,7-四 氢-6-[(5-取代-1,3,4-噁二唑)甲基]噻吩并[2,3-c]吡啶类化 合物方法. 以芳香醛和取代的酰肼类化合物为原料, 乙 醇为溶剂, 在微波辅助下纳米 $\left(\mathrm{ZnO}-\mathrm{TiO}_{2}\right)$ 催化取得 $87 \%$ 以上的产率(Eq. 6). 试验还研究了这类化合物的抑菌效 果, 可以作为一种潜在的抑菌药物.

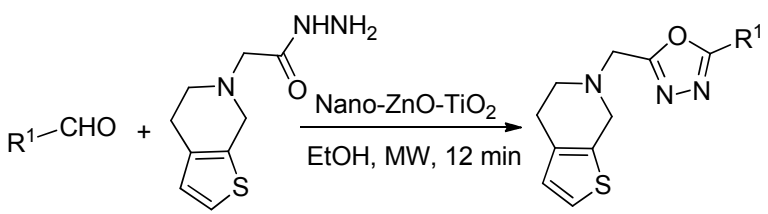

2014 年, Murty 等 ${ }^{[32]}$ 利用纳米 $\mathrm{CuO}$ 为催化剂, 催化 $N$-芳基- $N$-酰肼衍生物中 $\mathrm{C}-\mathrm{H}$ 键断裂形成 $\mathrm{C}-\mathrm{O}$ 键, 得 到 1,3,4-噁二唑类化合物, 产率较高, 并且催化剂可以 回收利用不影响其催化活性, 但该方法使用 DMSO 为 溶剂, 产物后处理比较复杂(Eq. 7).

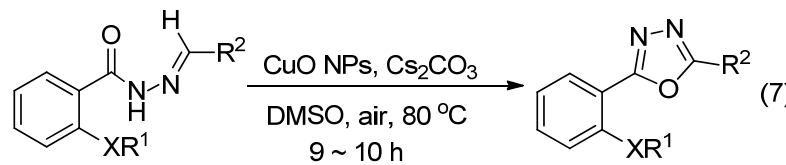

\section{3 纳米金属氧化物催化含 3 个氮原子杂环化合物合} 成

2013 年, Kamal 等 ${ }^{[33]}$ 设计了用纳米 $\mathrm{Fe}_{2} \mathrm{O}_{3}$ 催化合成 2,4,5-三取代-1,2,3-三唑类化合物的新方法. 通过查尔酮 类化合物、叠氮化钠和卤代芳基类化合物三组分串联反 应，可以立体选择性地合成芳基取代的三唑类化合物 (Eq. 8). 通过反应条件的控制实验, 发现反应中的氧化 剂来自于空气中的氧气。该合成方法底物适用范围广, 产物产率高, 并且催化剂可以回收利用没有明显的催化 活性的变化. 但使用 DMSO 为溶剂对环境污染大, 叠氮 化钠剧毒，易爆炸，后处理相对复杂.

端炔和叠氮类化合物催化合成三氮唑类化合物的 反应也有广泛的报道, 2013 年, Jana 和 Islam 等 ${ }^{[34]}$ 引入 种石墨烯为载体的 $\gamma-\mathrm{Fe}_{2} \mathrm{O}_{3}$ 纳米粒子 $\left(\mathrm{G}-\gamma-\mathrm{Fe}_{2} \mathrm{O}_{3}\right)$ 催化剂
在温和的条件下合成三氮唑类化合物，使用水作为溶 剂, 在氩气保护下进行(Eq. 9).
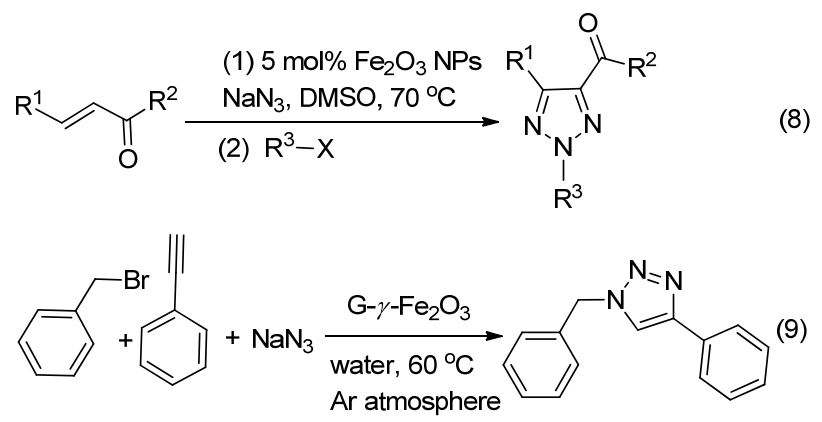

2016 年, Paul 等 ${ }^{[35]}$ 采用 $\mathrm{Cu}(0)-\mathrm{Fe}_{3} \mathrm{O}_{4}$ 负载在二氧化 硅上 $\left(\mathrm{Cu}(0)-\mathrm{Fe}_{3} \mathrm{O}_{4} @ \mathrm{SiO}_{2} / \mathrm{NH}_{2}\right)$ 的新型催化剂一锅法高效 合成 1,4-二取代-1,2,3-三唑类化合物，该方法减少了有 毒叠氮化合物的使用，而且以水为溶剂，反应在室温条 件下进行, 产率高达 97\% (Scheme 5). 该反应更加绿色 环保，适用性更广阔。

$$
\begin{aligned}
& \mathrm{R}^{1-\mathrm{NH}_{2}} \underset{\text { (ii) } \mathrm{NaN}_{3}}{\stackrel{\text { (i) Conc. } \mathrm{HCl}: \mathrm{H}_{2} \mathrm{O}(V: V=1: 1), \mathrm{NaNO}_{2}\left(0 \sim 5^{\circ} \mathrm{C}\right)}{\longrightarrow}}\left[\mathrm{R}^{1} \mathrm{~N}_{3}\right]
\end{aligned}
$$

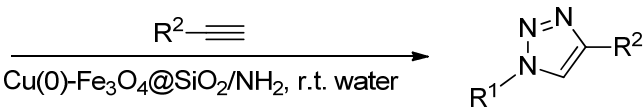

图式 5 室温水相下纳米 $\mathrm{Cu}(0)-\mathrm{Fe}_{3} \mathrm{O}_{4} @ \mathrm{SiO}_{2} / \mathrm{NH}_{2}$ 催化三唑类 化合物的合成

Scheme 5 Synthesis of triazole derivatives catalyzed by $\mathrm{Cu}(0)-\mathrm{Fe}_{3} \mathrm{O}_{4} @ \mathrm{SiO}_{2} / \mathrm{NH}_{2} \mathrm{NPs}$ in water at room temperature

\section{2 纳米金属氧化物催化多环含氮杂环化合物的 合成}

\section{1 含有两个环的含氮杂环类化合物的合成}

\section{1 .1 苯并嚊唑的合成}

由纳米氧化物合成苯并啞唑类化合物的方法被广 泛报道, 以邻氨基苯酚为原料, 2013 年, Vahdat 等 ${ }^{[36]}$ 应 用纳米 $\mathrm{SnO}_{2}$ 作为一种绿色可回收催化剂, 用乙醇作为 溶剂, 催化邻氨基苯酚类衍生物分别与芳香醛类化合物 和原甲酸甲酯在室温条件下反应，分别得到芳基取代的 苯并噁唑衍生物和烷基取代的苯并惡唑衍生物(Eq. 10). 这种合成方法产率高，催化剂用量少且可多次回收使 用，合成时间仅为 $30 \mathrm{~min}$ 左右，有广泛的应用前景. 2014 年, Banerjee 等 ${ }^{[37]}$ 利用纳米 $\mathrm{ZnO}$ 催化剂在室温下催 化合成了一系列有生物活性的 2-芳基-1,3-苯并噁唑的 衍生物. 当使用 2-氨基苯硫酚为原料时，该方法同时适 用于合成 1,3-苯并噁唑类化合物，加入催化剂后，反应 时间大大缩短到 $8 \mathrm{~min}$ ，产率高达 90\%以上(Eq. 11). 
2015 年, Maleki 等 ${ }^{[38]}$ 设计了一种 $\mathrm{Ag}$ 负载在 $\mathrm{TiO}_{2}$ 上的纳 米粒子 $\left(\mathrm{Ag} @ \mathrm{TiO}_{2}\right)$ 催化剂, 应用于一锅法水相合成苯并 啞唑类衍生物, 该反应中由于催化剂的使用, 大大拓展 了反应原料的范围, 邻氨基苯酚可以分别与不同的芳香 醛、芳香酰胺、羧酸、原甲酸酯、芳香酰氯类化合物反 应制得目标产物, 并且反应在室温条件下进行, 反应时 间为 $5 \mathrm{~min}$ 左右(Eq. 12).
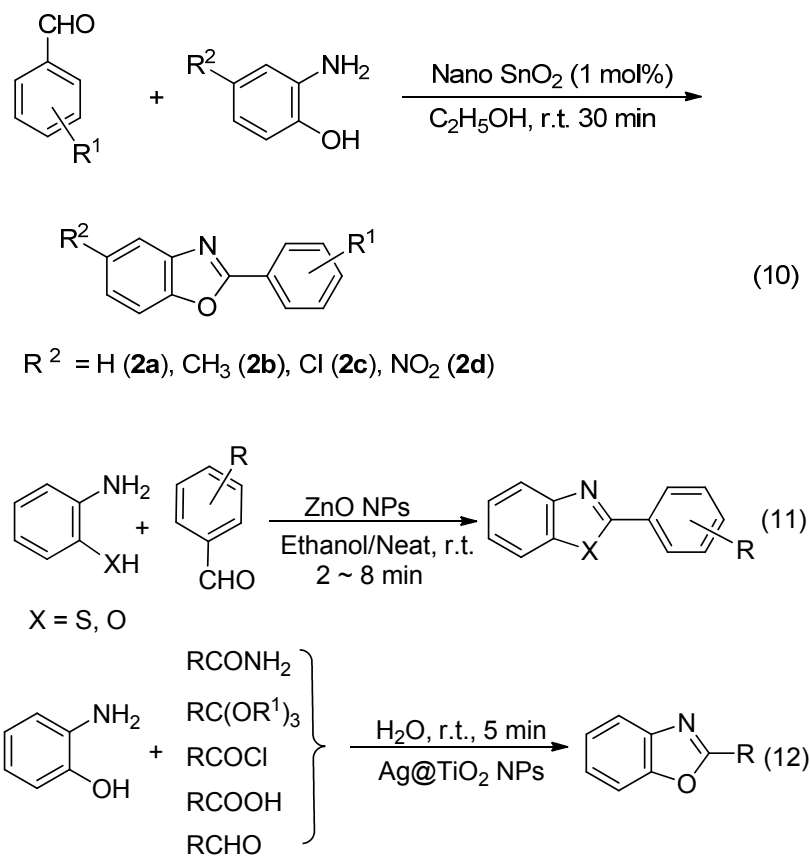

\subsection{2 苯并咪唑的合成}

纳米氧化物催化剂催化由不同原料合成苯并咪唑 类化合物的研究有广泛报道, Shiraishi 等 ${ }^{[39]}$ 报道了在光 和 $\mathrm{Pt}$ 负载在 $\mathrm{TiO}_{2}$ 纳米粒子为催化剂同时催化下, 邻苯 二胺和伯醇反应在 $\mathrm{N}_{2}$ 保护室温条件下合成 2 位取代的 苯并咪唑类化合物, 产率高达 $99 \%$. Karami 等 ${ }^{[40]}$ 以可回 收的磁性 $\mathrm{Fe}_{3} \mathrm{O}_{4}$ 为催化剂, 无溶剂条件下以邻苯二胺和
原甲酸三甲酯或原乙酸三甲酯为原料合成 2 位取代的苯 并咪唑类化合物. Alinezhad 等 ${ }^{[41]}$ 利用纳米 $\mathrm{ZnO}$ 催化邻 苯二胺和甲酸在无溶剂条件下合成苯并咪唑类衍生物, 原料简单易得，反应条件也比较温和. Majee 等 ${ }^{[42]}$ 发明 了以纳米 $\mathrm{In}_{2} \mathrm{O}_{3}$ 为催化剂合成 1,2-二取代的苯并咪唑类 化合物, 用乙醇和水的体积比 $2: 1$ 为溶剂, 绿色环保, 反应条件温和，产率在 $84 \% \sim 92 \%$ 之间(Scheme 6).

在由邻二苯胺合成苯并咪唑的同时，同一种催化剂 对不同的反应原料也有很好的适用性，由邻氨基苯酚和 邻氨基苯硫酚为原料分别可以得到苯并噁唑及苯并噻 唑. 2013 年, Mandal 等 ${ }^{[43]}$ 将纳米 $\mathrm{CuO}$ 颗粒负载在二氧化 硅上, 作为一种新的催化剂催化一系列的苯并杂环类化 合物的反应，如苯并噁唑、苯并咪唑、苯并噻唑等. 该 反应利用甲醇为溶剂, 在室温下反应 $4 \mathrm{~h}$, 催化剂可多 次回收利用，反应应用范围广，产物产率高. 2014 年, Wang 等 ${ }^{[44]}$ 设计采用纳米 $\mathrm{CuFe}_{2} \mathrm{O}_{4}$ 为催化剂合成这三类 衍生物, 并证明空气中氧气的存在使反应中间体氧化, 最终得到杂环产物. 2013 年, Nagarkar 等 ${ }^{[45]}$ 利用非均相 可回收纳米 $\mathrm{CeO}_{2}$ 为催化剂用同样的原料合成苯并咪 唑、苯并惡唑及苯并噻唑类衍生物, 反应在室温条件下 进行, 反应时间仅为 $30 \mathrm{~min}$ 左右. 采用水作为溶剂, 更 加绿色环保，并且底物适用范围广，对不同种类的醛 (芳香醛、杂环芳香醛、不饱和醛、脂肪醛)为原料均得 到高产率的化合物. Hajipour 等 ${ }^{[46]}$ 通过对此类化合物与 乳腺癌细胞雌性激素的受体之间的作用研究表明，这类 化合物是一类潜在的雌性激素抑制剂(Scheme 6).

在苯并咪唑类化合物合成中，采用不同的活泼羰基 的化合物为原料时，同样的催化剂可能得到完全不同的 产物. 2014 年, $\mathrm{Pal}$ 等 ${ }^{[47]}$ 使用磁性纳米 $\mathrm{Fe}_{3} \mathrm{O}_{4}$ 在无溶剂条 件下催化两种化合物的合成, 当使用邻苯二胺和醛类为 原料时，合成得到 1,2-苯并咪唑类衍生物; 当使用邻苯

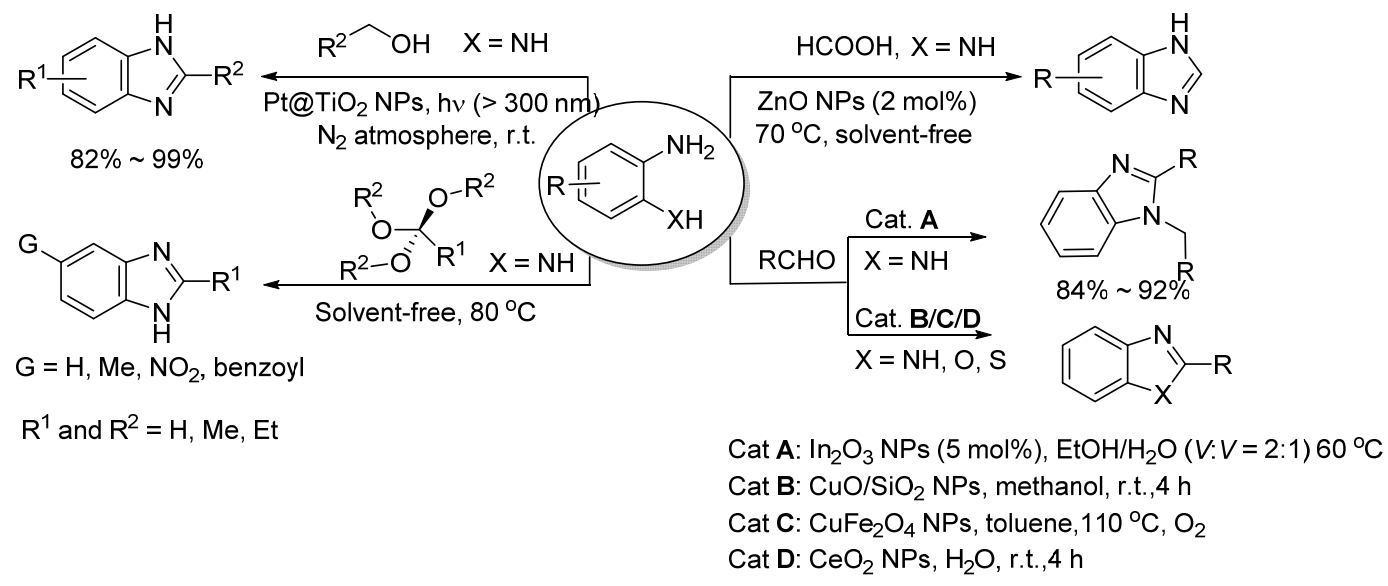

图式 6 不同纳米金属氧化物催化苯并咪唑类化合物的合成

Scheme 6 One-pot synthesis of benzimidazole derivatives using different nanoparticles 
二胺和芳香酮类或脂肪酮类为原料时，合成得到 1,5-吩 噻嗪类衍生物. 反应温度为 $80{ }^{\circ} \mathrm{C}$, 反应时间为 $10 \mathrm{~min}$ 左右. 同年, Maleki 等 ${ }^{[48]}$ 设计合成一种生物大分子(壳聚 糖)负载的磁性纳米非均相催化剂, 使这两类化合物的 合成向更加环境友好的方向发展, 而且反应均在室温下 进行, 溶剂为乙醇, 产率高达 97\%. 这种合成方法更加 简单易行, 合成条件温和, 催化剂可重复利用, 原子经 济性高(Scheme 7).

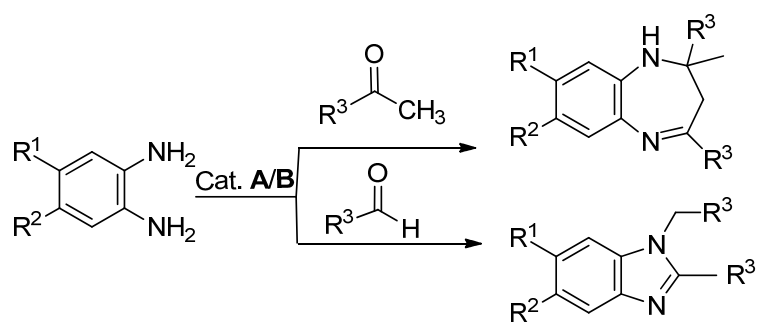

Cat. A: $\mathrm{Fe}_{3} \mathrm{O}_{4} 6 \mathrm{~mol} \%$, solvent free, $80^{\circ} \mathrm{C}, 10 \sim 15 \mathrm{~min}$

Cat. B: $\mathrm{Fe}_{3} \mathrm{O}_{4} /$ chitosan, $\mathrm{EtOH}$, r.t

图式 7 不同纳米金属氧化物催化苯并咪唑和 1,5-吩噻嗪类衍 生物的合成

Scheme 7 Synthesis of benzimidazoles and 1,5-benzodiazepines using different NPs

2015 年, Singh 等 ${ }^{[49]}$ 通过离子液体负载的纳米 $\mathrm{ZnO}$ 颗粒, 使用球磨法在室温下选择性地催化合成 1,2-双取 代的苯并咪唑类衍生物. 在协同催化的作用下, 催化剂 用量为 $0.2 \mathrm{~mol} \%$, 反应时间为 $22 \mathrm{~min}$, 球磨转速为 600 $\mathrm{r} / \mathrm{min}$, 产物全部为二取代的苯并咪唑衍生物(Eq. 13). 该方法产物后处理简单, 不需要溶剂参与, 催化剂需要 量少且可以回收. 与其他反应方法相比, 呈现出很好的 环境友好性, 有很好的工业应用前景.

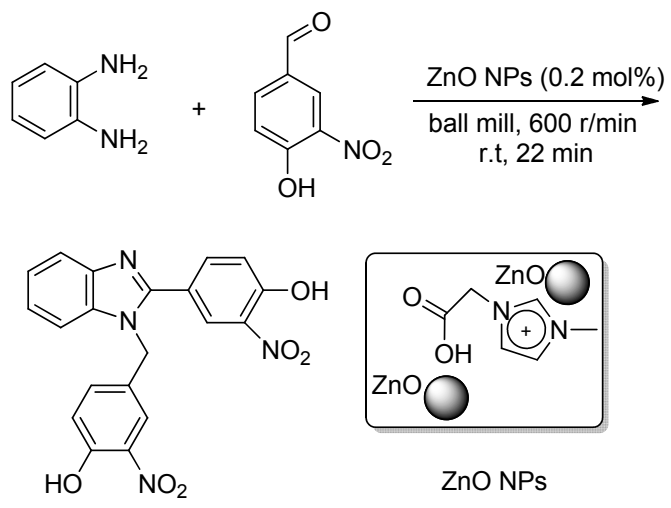

\subsection{3 苯并噻唑的合成}

2015 年, Heydari 等 ${ }^{[50]}$ 采用一种新的途径合成 2-氨 基苯并噻唑衍生物, 利用邻碘苯胺和异硫氰酸酯为原 料, 用改性后的纳米 $\mathrm{Fe}_{3} \mathrm{O}_{4}\left[\mathrm{Fe}_{3} \mathrm{O}_{4} @ E D T A-\mathrm{Cu}(\mathrm{II})\right]$ 为催 化剂, 以水为溶剂, 高效地得到目标产物. 该反应催化
条件温和，但催化过程中要加入碱性物质三乙烯二胺 (DABCO)和添加剂四丁基溴化铵(TABA)，使反应复杂. 该反应是合成 2-氨基苯并噻唑的一种重要方法(Eq. 14).

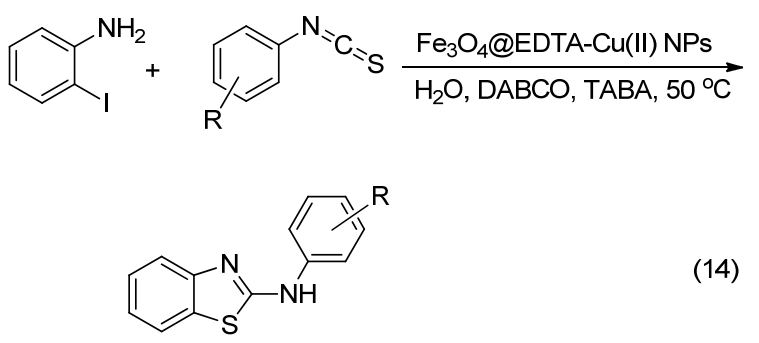

2015 年, Amoozadeh 等 ${ }^{[51]}$ 在无溶剂条件下用磺酸负 载的纳米 $\mathrm{TiO}_{2}$ 催化剂成功催化 2-氨基苯硫酚和芳香醛 类化合物合成苯并噻唑类衍生物, 带有不同电子基团的 芳香醛为原料参与反应均得到良好的产率. 2016 年, Bahrami 等 ${ }^{[52]}$ 同样引入纳米 $\mathrm{TiO}_{2}$ 作为催化剂, 与 $\mathrm{H}_{2} \mathrm{O}_{2}$ 共同催化苯并咪唑和苯并噻唑两类化合物的合成(Eq. 15). 原料分别为取代的邻苯二胺或 2-氨基苯硫酚与系 列的芳香醛类化合物. 反应简单易操作, 用光照 $50{ }^{\circ} \mathrm{C}$ 下反应，反应过程污染小，反应时间短，产物产率高. 不同取代的原料均取得较高产率，但是进一步实验证 明，该方法不适用于催化邻氨基苯酚和芳香醛合成苯并 啞唑类化合物.

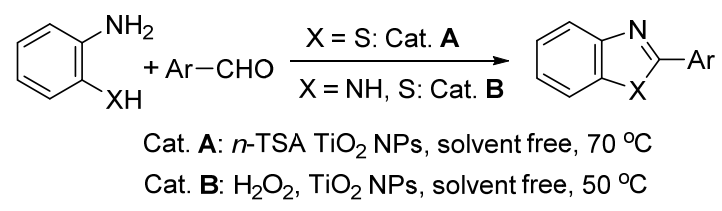

2016 年, $\mathrm{Paul}$ 等 ${ }^{[35]}$ 同样采用 $\mathrm{Cu}(0)-\mathrm{Fe}_{3} \mathrm{O}_{4}$ 负载在二 氧化硅上 $\left[\mathrm{Cu}(0)-\mathrm{Fe}_{3} \mathrm{O}_{4} @ \mathrm{SiO}_{2} / \mathrm{NH}_{2}\right]$ (Scheme 15)中的催 化剂结构)的新型催化剂一锅法高效合成 2-取代的苯并 噻唑类化合物. 催化剂重复使用 6 次催化活性没有明显 变化, 反应在水溶剂中进行, 这种合成方法将在绿色有 机合成中有更广泛的应用(Eq. 16).
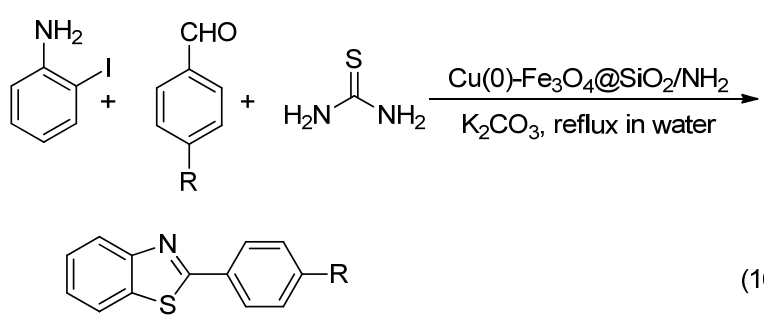

\section{1 .4 喹喔啉类化合物的合成}

有很多报道关于纳米氧化颗粒催化喹喔啉类化合 物的合成，原料通常为邻苯二胺和 1,2-二羰基化合物, 报道过的催化剂有 $\mathrm{Fe}_{3} \mathrm{O}_{4} @ \mathrm{SiO}_{2} /$ 席夫碱类纳米粒子[53]、 
纳米 $\mathrm{ZrO}_{2}$ 催化剂 ${ }^{[54]}$ 、淀粉为负载的纳米 $\mathrm{ZrO}_{2}$ 和磁铁矿 颗粒 $\left(\mathrm{ZrOL}_{2} @ \mathrm{SMNP}\right)^{[55]}$ 、纳米 $\mathrm{Co}$ 粒子 ${ }^{[56]}$ 、负载在 $\mathrm{SiO}_{2}$ 聚甲基丙烯腈酯上的纳米 $\mathrm{Fe}_{3} \mathrm{O}_{4}$ 颗粒 $\left(\mathrm{Fe}_{3} \mathrm{O}_{4} @ \mathrm{SiO}_{2}\right.$-imidPMA) $)^{[57]}$ 等(Eq. 17).

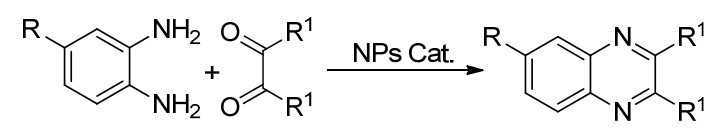

2014 年, $\mathrm{Lee}$ 等 ${ }^{[58}$ 利用纳米 $\mathrm{CeO}_{2}$ 为催化剂高效催化 三组分合成 2-氨基喹喔啉类化合物, 反应原料为邻苯二 胺、芳香醛、异腈类衍生物, 反应取得很高产率, 并且 用水为溶剂, 反应过程绿色环保. 值得注意的是, 当适 用靛红为醛类化合物参与三组分反应时, 并没有获得相 应的螺环吲哚类化合物, 而是得到了并环的吲哚并喹喔 啉类化合物. 醛基在纳米氧化物的作用下活化, 得到亚 胺离子与异腈发生亲核取代反应生成中间体通过环加
成反应，最终被氧化生成喹喔啉类化合物. 可以总结由 纳米粒子参与的过程大都生成了亚胺中间体 (Scheme 8).

2015 年, Wang 等 ${ }^{[59]}$ 设计合成一种有孔隙的 $\mathrm{Fe}_{3} \mathrm{O}_{4} @ \mathrm{Cu}_{2} \mathrm{O}$ 纳米粒子作为合成喹喔啉类化合物的高效 可回收催化剂, 这类催化剂为合成喹喔啉化合物提供了 新的途径, 采用原料为邻苯二胺和端炔类化合物, 加入 添加剂二甲氨基吡啶(DMAP) 和碳酸铯 $\left(\mathrm{Cs}_{2} \mathrm{CO}_{3}\right)$, 在甲 苯为溶剂条件下回流反应. 催化剂可回收多次使用且选 择性高, 当邻苯二胺上带有吸电子性的取代基团时, 产 物产率为零(Eq. 18).

\subsection{5 吡唑并酞嗪酮类化合物的合成}

2012 年, Azarifar 等 ${ }^{[60]}$ 利用纳米 $\mathrm{ZnO}$ 为催化剂合成 了一系列吡咯并唒嗪酮类化合物。该方法具有反应时间 短, 产物后处理简单且产率高的优点(Eq. 19).

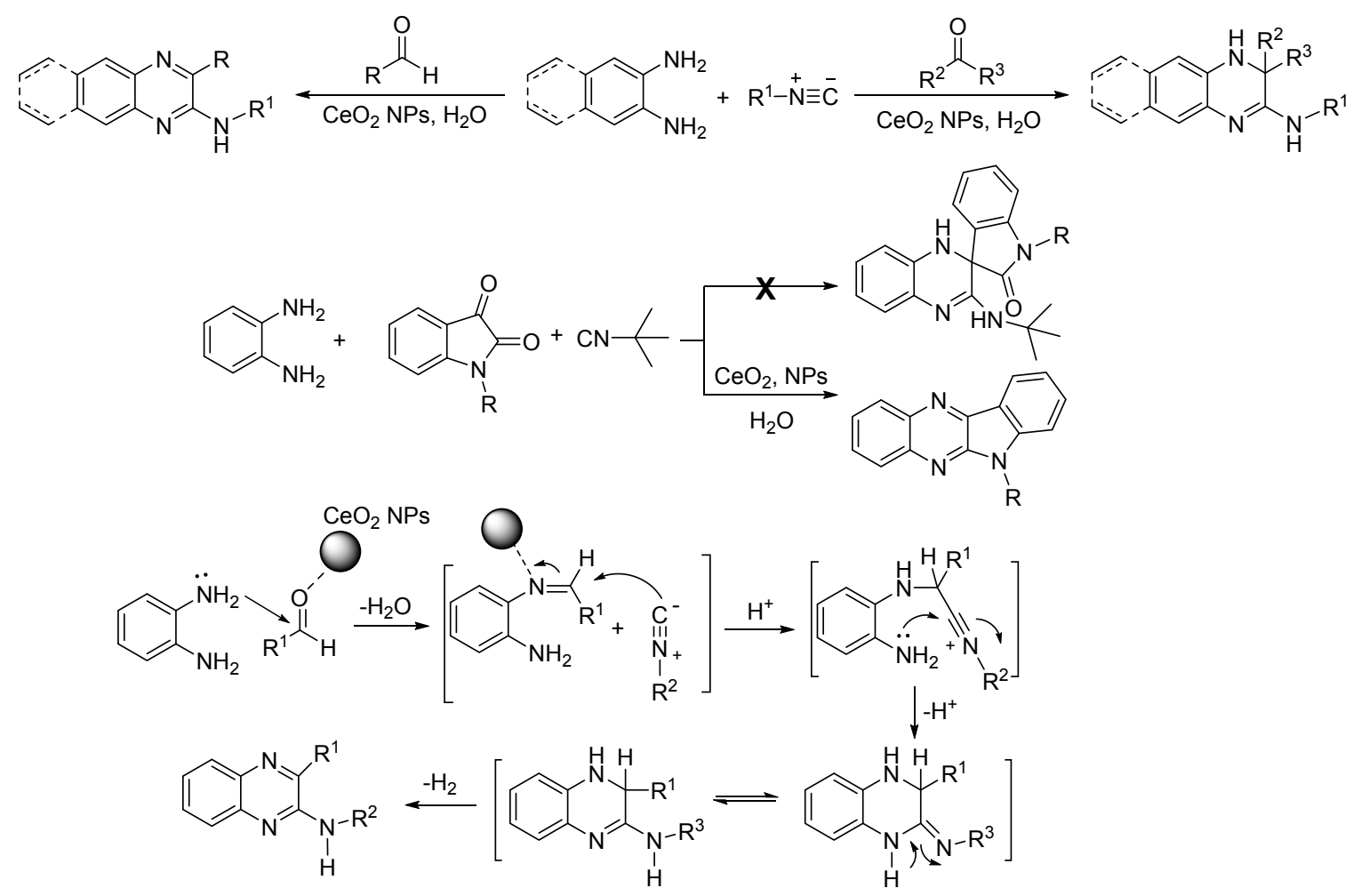

图式 8 纳米 $\mathrm{CeO}_{2}$ 粒子催化合成喹喔啉类化合物机理图

Scheme 8 The possible mechanism for the formation of quinaxolin-2-amine derivatives catalyzed by $\mathrm{CeO}_{2} \mathrm{NPs}$

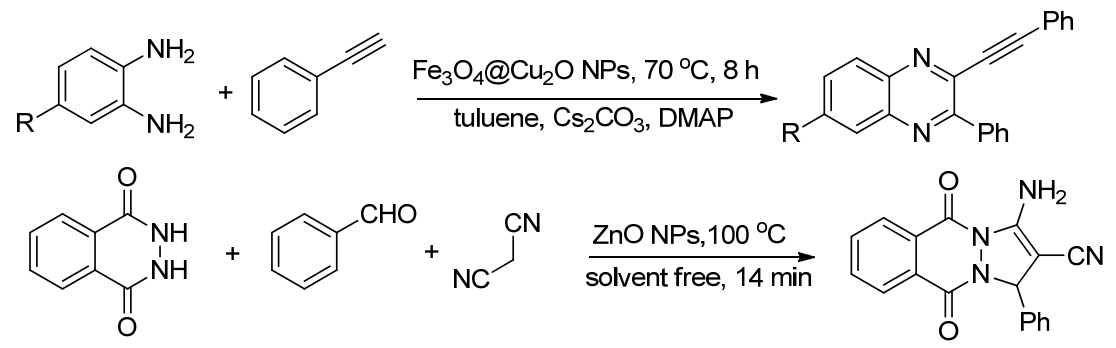




\subsection{6 咪唑并吡啶类化合物的合成}

2015 年, Foroumadj 等 ${ }^{[61]}$ 引入 $\gamma$ 构型的 $\mathrm{Fe}_{2} \mathrm{O}_{3}$ 纳米粒 子催化剂 $\gamma-\mathrm{Fe}_{2} \mathrm{O}_{3}-\mathrm{Hap}-\left(\mathrm{CH}_{2}\right)_{3}-\mathrm{NHSO}_{3} \mathrm{H}$, 在无溶剂条件 下, 利用三组分一锅高效合成了一类喹啉与咪唑并吡啶 连接的稠杂环的化合物(Eq. 20).

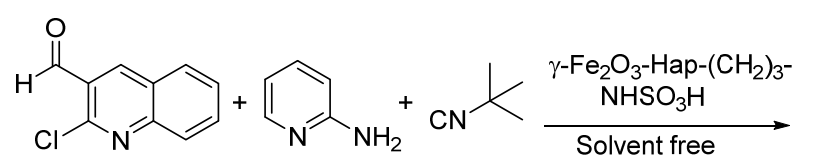<smiles>CC(C)(C)Nc1c(-c2cc3ccccc3nc2Cl)nc2ccccn12</smiles>

2016 年, Shrivastava 等 ${ }^{[62]}$ 成功设计可回收的非均相 纳米 $\mathrm{ZnO}$ 催化剂, 在乙醇为溶剂回流的条件下, 合成了 一类和吡唑相连的咪唑并吡啶类稠杂环化合物, 这两类 合成途径操作简单, 反应时间少, 催化剂重复利用催化 活性没有明显减少, 反应条件温和无毒, 高效构建了稠 杂环的咪唑并吡啶类化合物的衍生物(Eq. 21).

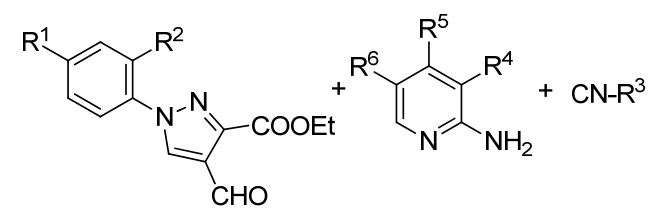<smiles>[R]Nc1c(-c2cn(-c3ccc([R])cc3[R])nc2C(=O)OCC)nc2c([R])c(C)c([R])cn12</smiles>

\section{1 .7 吡喃并吡唑类化合物的合成}

2014 年, Das 等 ${ }^{[63]}$ 利用未被修饰 $\mathrm{SnO}_{2}$ 量子点催化多 取代的吡喃并吡唑类和螺环吲哚类衍生物的合成取得 了很好的效果. 量子点是三个维度尺寸都在 $100 \mathrm{~nm}$ 以 下的纳米材料, 量子点具有许多独特的纳米性质. 催化 剂的量少并且产物产率高, 对不同取代基团的原料适用 性好. 还考察了油酸修饰的 $\mathrm{SnO}_{2}$ 量子点, $\mathrm{SnO}_{2}$ 纳米花等 不同形貌的纳米 $\mathrm{SnO}_{2}$ 形貌对催化反应的影响, 结果表 明未修饰的 $\mathrm{SnO}_{2}$ 量子点催化效率最高. 催化剂重复使 用 6 次而不影响其催化活性(Eq. 22)

\section{2 含有多个环的含氮杂环类化合物的合成}

2013 年, Majee 等 ${ }^{[64]}$ 设计一种纳米 $\mathrm{CuO}$ 催化异吲哚 喹唑啉酮类化合物合成方法, 反应水溶液中进行. 水通<smiles>[R]OC(=O)CC#CC(C)=O</smiles>

过氢键与反应物和催化剂结合, 在加速反应中起到重要 的电子桥梁作用. 这种方法反应适用性广, 催化靛红酸 酐，2-甲酰基苯甲酸和胺类化合物反应，其中脂肪胺和 芳香胺为原料均取得较高的产率, 反应中催化剂可以重 复使用多次, 这种异吲哚并喹唑啉酮类化合物的绿色的 合成方法在工业上有很大的应用前景(Eq. 23).
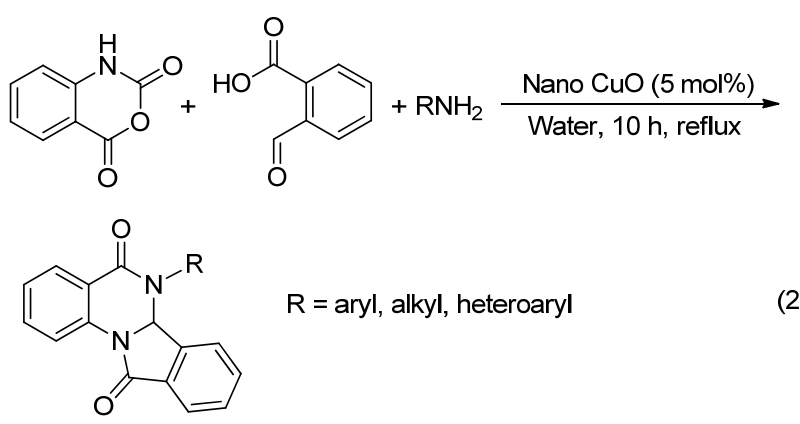

2015 年, Yavari 等 ${ }^{[65]}$ 设计了一种新型的非均相核壳 结构的纳米粒子催化剂 $\mathrm{Fe}_{3} \mathrm{O}_{4} / \mathrm{SiO}_{2} /\left(\mathrm{CH}_{2}\right)_{3} \mathrm{~N}^{+} \mathrm{Me}_{3} \mathrm{Br}_{3}{ }^{-}$, 在无溶剂的条件下催化合成苯并噻唑及咪唑和嘧啶等 复杂稠环含氮化合物. 由于催化剂的引入, 大大缩短了 反应时间，提高了产物产率. 该方法底物适用性好，反 应操作及后处理简单, 成为绿色合成复杂稠环化合物的 一种新方法(Eq. 24).

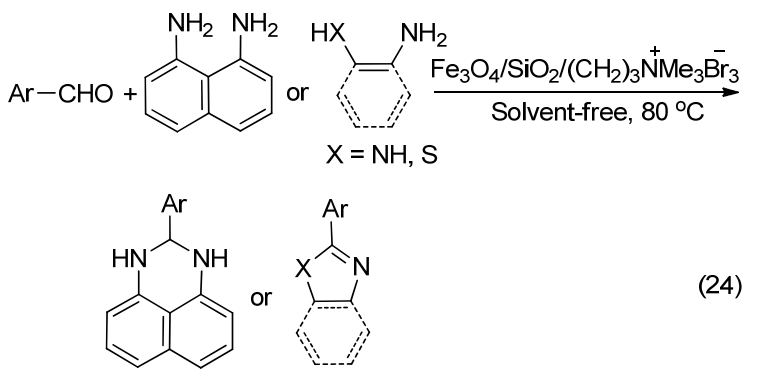

2015 年, Maleki 等 ${ }^{[66]}$ 利用磁性 $\mathrm{Fe}_{3} \mathrm{O}_{4}$ 粒子负载在壳 聚糖上作为催化剂, 在温和的反应条件下 $\left(40{ }^{\circ} \mathrm{C}\right.$, 乙醇 为溶剂)催化 2-氨基苯并噻唑或 2-氨基苯并咪唑、二甲 基环已烷二酮与系列芳香醛反应，一锅法高产率地得到 四环的稠杂环苯并咪唑并喹唑啉酮类化合物. 这类催化 剂对环境无污染且可回收多次使用, 并且合成方法具有 
很多优点, 如反应过程中避免了有毒溶剂的使用, 过程 简单易操作，产率高(Eq. 25).

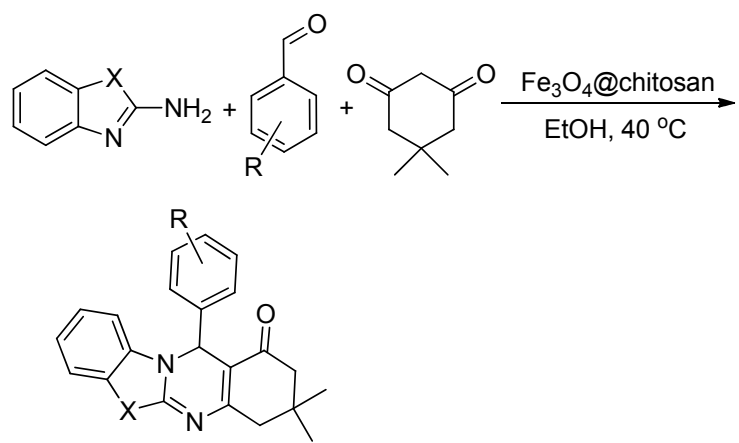

本课题组在纳米金属氧化物催化合成喹唑啉酮衍 生物的合成研究取得一定的进展, 喹唑啉酮类化合物因 其特殊的含氮杂环骨架及特殊的生理活性而吸引了合 成研究者的广泛关注. 本课题组使用纳米 $\mathrm{CuO}$ 为催化 剂, 靛红酸酐、芳香醛、芳香胺为原料，一锅法合成了 2,3-2(H)二取代的喹唑啉酮类化合物, 当使用无机盐氯 化铵替代芳香胺作为氮源时, 得到了 3 位取代的喹唑啉 酮类化合物 ${ }^{[67]}$. 利用纳米 $\mathrm{CeO}_{2}$ 为催化剂合成了螺环吲
哚喹唑啉酮类化合物 ${ }^{[68]}$ 及 3 -酰胺基喹唑啉酮类化合 物 ${ }^{[69]}$. 这两类化合物分别具有一定的抗细菌及抗真菌 的作用, 利用超声辅助的方法, 在纳米氧化铜催化条件 下得到硫代的喹唑啉酮类化合物, 该类化合物对植物病 原菌有着良好的抑制活性 ${ }^{[70]}$. 在纳米 $\mathrm{TiO}_{2}$ 的催化下, 靛 红酸酐、邻甲酰基苯甲酸分别与肼和酰肼类化合物反应, 可得到喹唑啉酮并酞嗪酮及 3-酰胺基喹唑啉酮并异吲 哚酮类化合物 ${ }^{[71]}$. 这几种合成方法简洁高效，反应条件 温和，同时取得了较高的产率(Scheme 9).

\section{3 结论}

综上所述，纳米金属氧化物因其材料结构及比表面 积的特殊性，良好的催化活性和可重复利用等优点被不 断开发和应用于多种含氮的稠杂环化合物的合成中，近 年来纳米金属氧化物不但自身可以作为催化剂，还可以 负载其他贵金属等作为催化剂, 使催化范围大大增加. 随着人们对新药的不断开发, 对催化合成方法的不断探 索，对催化剂的进一步修饰，得到高效、经济、绿色的 合成方法仍将是今后研究的热点. 因此纳米金属氧化物 催化剂将在催化合成方面有巨大的应用前景.

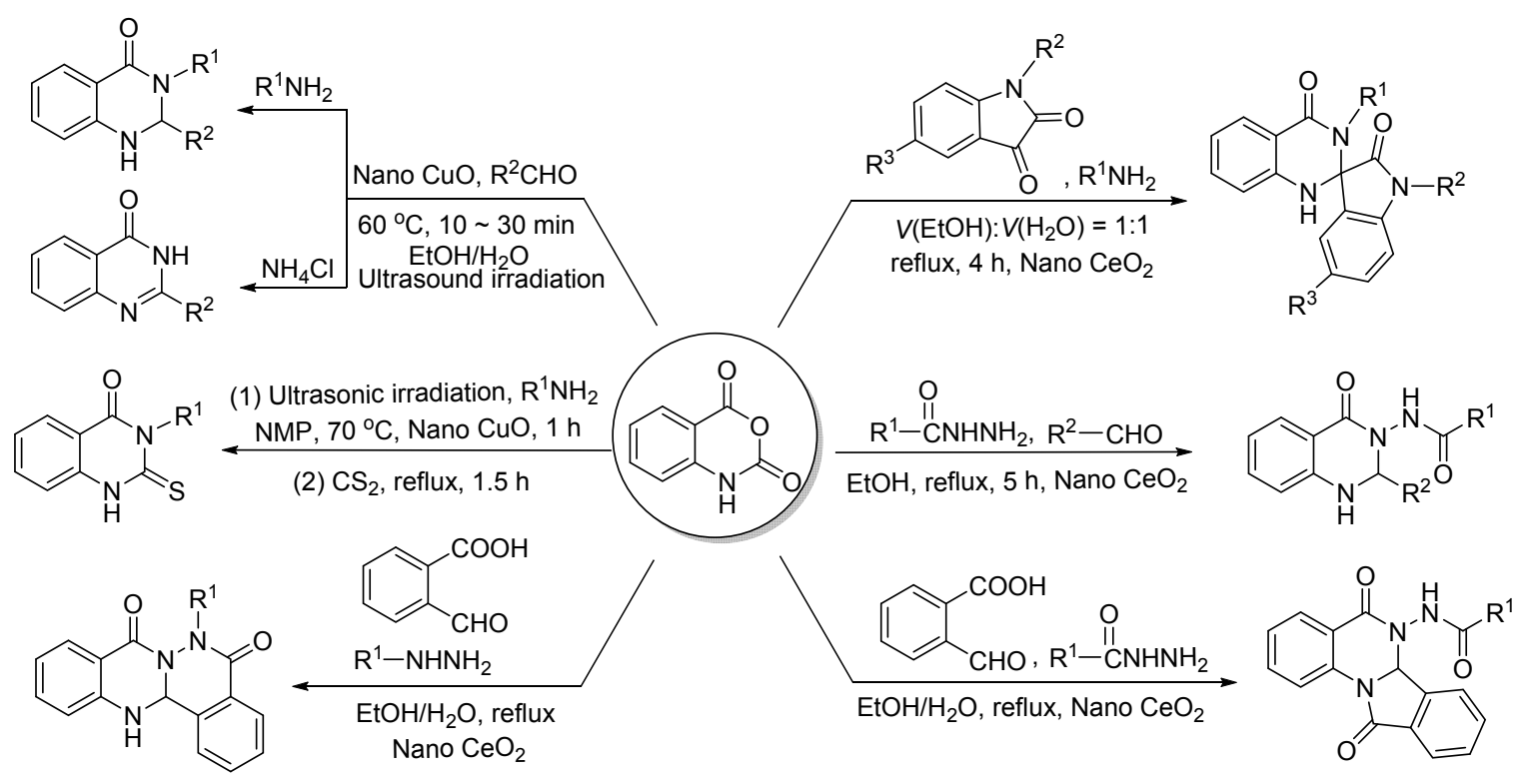

图式 9 本课题组用纳米金属氧化物在合成喹唑啉酮类含氮杂环类化合物

Scheme 9 Synthesis of $N$-fused quinazolinones catalyzed by nanoparticles in our group

\section{References}

[1] Shafiee, A. Eur. J. Med. Chem. 2015, 97, 334.

[2] Rani, R.; Granchi, C. Eur. J. Med. Chem. 2015, 97, 505.

[3] Yang, R.; Gao, Z.-F.; Zhao, J.-Y.; Li, W.-B.; Zhou, L.; Miao, F. J. Agric. Food Chem. 2015, 63, 1906.

[4] Manivannan, E.; Chaturvedi, S. C. Bioorg. Med. Chem. 2011, 19, 4520 .

[5] Giardina, D.; Martarelli, D.; Sagratini, G.; Angeli, P.; Ballinari, D.;
Gulini, U.; Melchiorre, C.; Poggesi, E.; Pompei, P. J. Med. Chem. 2009, 52, 4951.

[6] Wermuth, C. G.; Schlewer, G.; Bourguignon, J. J.; Maghioros, G.; Bouchet, M. J.; Moire, C.; Kan, J. P.; Worms, P.; Biziere, K. J. Med. Chem. 1989, 32, 528.

[7] Rueda, L.; Castellote, I.; Castro-Pichel, J.; Chaparro, M. J.; de la Rosa, J. C.; Garcia-Perez, A.; Gordo, M.; Jimenez-Diaz, M. B.; Kessler, A.; Macdonald, S. J. F.; Martinez, M. S.; Sanz, L. M.; Gamo, F. J.; Fernandez, E. ACS Med. Chem. Lett. 2011, 2, 840. 
[8] Wang, J.; Tan, H.; Li, Y.; Ma, Y.; Li, Z.; Guddat, L. W. J. Agric. Food Chem. 2011, 59, 9892.

[9] Hu Q. Z.; Qin Y; Xi H. T; Sun X. Q. Chin. J. Synth. Chem. 2011, 19, 480 (in Chinese). (胡泉子, 秦瑗, 席海涛, 孙小强, 合成化学, 2011, 19, 480.)

[10] Yang, W.; Chen, J.; Huang, X.; Ding, J.; Liu, M.; Wu, H. Org. Lett. 2014, 16, 5418 .

[11] Ding, Z. W.; Tan, Q. T.; Liu, B. X.; Zhang, K.; Xu, B. Acta Chim. Sinica 2015, 73, 1302 (in Chinese). (丁正伟, 谭启涛, 刘秉新, 张可, 许斌, 化学学报, 2015, 73, 1302.)

[12] Zhao, J. B.; Zhang, Q. Acta Chim. Sinica 2015, 73, 1235 (in Chinese). (赵金针, 张前, 化学学报, 2015, 73, 1235.)

[13] Zhang, Z. R.; Zheng, X. L.; Guo, C. B. Chin. J. Org. Chem. 2016, 36, 1241 (in Chinese). (张钊瑞, 郑晓霖, 郭长涁, 有机化学, 2016, 36, 1241.)

[14] Ji, Y. G.; Wu, L.; Fan, Q. H. Acta Chim. Sinica 2014, 72, 798 (in Chinese). (季益刚，吴磊，范青华，化学学报, 2014, 72, 798.)

[15] Elwahy, A. H. M.; Shaaban, M. R. RSC Adv. 2015, 5, 75659.

[16] Teimouri, A.; Chermahini, A. N. Chin. J. Chem. 2012, 30, 372.

[17] Ma, F. P.; Li, P. H.; Li, B. L.; Mo, L. P.; Liu, N.; Kang, H. J.; Liu, Y. N.; Zhang, Z. H. Appl. Catal. A: Gen. 2013, 457, 34.

[18] Li, B.; Hu, H.; Mo, L.; Zhang, Z. RSC Adv. 2014, 4, 12929.

[19] Li, B.; Zhang, M.; Hu, H.; Du, X.; Zhang, Z. New J. Chem. 2014, 38, 2435.

[20] Sabbaghan, M.; Ghalaei, A. J. Mol. Liq. 2014, 193, 116.

[21] Hajinasiri, R.; Hossaini, Z.; Sheikholeslami-Farahani, F. Comb. Chem. High Throughput Screening 2015, 18, 42.

[22] Azgomi, N.; Mokhtary, M. J. Mol. Catal. A: Chem. 2015, 398, 58.

[23] Sobhani, S.; Honarmand, M. Appl. Catal. A: Gen. 2013, 467, 456.

[24] Eshghi, H.; Khojastehnezhad, A.; Moeinpour, F.; Rezaeian, S.; Bakavoli, M.; Teymouri, M.; Rostami, A.; Haghbeen, K. Tetrahedron 2015, 71, 436.

[25] Teimouri, A.; Chermahini, A. N. J. Mol. Catal. A: Chem. 2011, $346,39$.

[26] Safari, J.; Zarnegar, Z. J. Chem. Sci. 2013, 125, 835.

[27] Zarnegar, Z.; Safari, J. RSC Adv. 2014, 4, 20932.

[28] Reddy, B.; Vijayakumar, V.; Arasu, M.; Al-Dhabi, N. Molecules 2015, 20, 19221.

[29] Mitra, S.; Bagdi, A. K.; Majee, A.; Hajra, A. Tetrahedron Lett. 2013, 54, 4982.

[30] Zakerinasab, B.; Nasseri, M. A.; Hassani, H.; Samieadel, M. M. Res. Chem. Intermed. 2015, 42, 3169.

[31] Sangshetti, J. N.; Dharmadhikari, P. P.; Chouthe, R. S.; Fatema, B.; Lad, V.; Karande, V.; Darandale, S. N.; Shinde, D. B. Bioorg. Med. Chem. Lett. 2013, 23, 2250.

[32] Murty, M. S. R.; Penthala, R.; Buddana, S. K.; Prakasham, R. S.; Das, P.; Polepalli, S.; Jain, N.; Bojja, S. Med. Chem. Res. 2014, 23, 4579 .

[33] Kamal, A.; Swapna, P. RSC Adv. 2013, 3, 7419.

[34] Salam, N.; Sinha, A.; Mondal, P.; Roy, A. S.; Jana, N. R.; Islam, S. M. RSC Adv. 2013, 3, 18087.

[35] Bhardwaj, M.; Jamwal, B.; Paul, S. Catal. Lett. 2016, 146, 629.

[36] Vahdat, S. M.; Raz, S. G.; Baghery, S. J. Chem. Sci. (Bangalore, India) 2014, 126, 579.

[37] Banerjee, S.; Payra, S.; Saha, A.; Sereda, G. Tetrahedron Lett. 2014, 55, 5515 .

[38] Maleki, B.; Baghayeri, M.; Vahdat, S. M.; Mohammadzadeh, A.; Akhoondi, S. RSC Adv. 2015, 5, 46545.

[39] Shiraishi, Y.; Sugano, Y.; Tanaka, S.; Hirai, T. Angew. Chem., Int.
Ed. 2010, 49, 1656.

[40] Karami, B.; Nikoseresht, S.; Khodabakhshi, S. Chin. J. Catal. 2012, 33, 298.

[41] Alinezhad, H.; Salehian, F.; Biparva, P. Synth. Commun. 2012, 42, 102.

[42] Santra, S.; Majee, A.; Hajra, A. Tetrahedron Lett. 2012, 53, 1974.

[43] Inamdar, S. M.; More, V. K.; Mandal, S. K. Tetrahedron Lett. 2013, 54, 579.

[44] Yang, D.; Zhu, X.; Wei, W.; Sun, N.; Yuan, L.; Jiang, M.; You, J.; Wang, H. RSC Adv. 2014, 4, 17832.

[45] Shelkar, R.; Sarode, S.; Nagarkar, J. Tetrahedron Lett. 2013, 54, 6986.

[46] Hajipour, A. R.; Khorsandi, Z.; Mortazavi, M.; Farrokhpour, H. RSC Adv. 2015, 5, 107822.

[47] Jamatia, R.; Saha, M.; Pal, A. K. RSC Adv. 2014, 4, 12826.

[48] Maleki, A.; Ghamari, N.; Kamalzare, M. RSC Adv. 2014, 4, 9416.

[49] Sharma, H.; Kaur, N.; Singh, N.; Jang, D. O. Green Chem. 2015, 17,4263 .

[50] Azizi, K.; Karimi, M.; Heydari, A. Tetrahedron Lett. 2015, 56, 812.

[51] Amoozadeh, A.; Azadeh, R. A.; Rahmani, S.; Salehi, M.; Kubicki, M.; Dutkiewicz, G. Phosphorus, Sulfur Silicon Relat. Elem. 2015, 190, 1874

[52] Bahrami, K.; Khodaei, M. M.; Naali, F. J. Exp. Nanosci. 2016, 11, 148.

[53] Esmaeilpour, M.; Sardarian, A. R. Green Chem. Lett. Rev. 2014, 7, 301.

[54] Jafarpour, M.; Rezapour, E.; Ghahramaninezhad, M.; Rezaeifard, A. New J. Chem. 2014, 38, 676.

[55] Jafarpour, M.; Rezaeifard, A. Transition Met. Chem. 2015, 41, 205.

[56] Rajabi, F.; Alves, D.; Luque, R. Molecules 2015, 20, 20709.

[57] Javidi, J.; Esmaeilpour, M. Mater. Res. Bull. 2016, 73, 409.

[58] Edayadulla, N.; Lee, Y. R. RSC Adv. 2014, 4, 11459.

[59] Wang, Z.; Hu, G.; Liu, J.; Liu, W.; Zhang, H.; Wang, B. Chem. Commun. 2015, 51, 5069.

[60] Azarifar, A.; Nejat-Yami, R.; Azarifar, D. J. Iran Chem. Soc. 2012, 10, 297.

[61] Mouradzadegun, A.; Ma'mani, L.; Mahdavi, M.; Rashid, Z.; Shafiee, A.; Foroumadi, A.; Dianat, S. RSC Adv. 2015, 5, 83530.

[62] Swami, S.; Devi, N.; Agarwala, A.; Singh, V.; Shrivastava, R. Tetrahedron Lett. 2016, 57, 1346.

[63] Paul, S.; Pradhan, K.; Ghosh, S.; De, S. K.; Das, A. R. Tetrahedron 2014, 70, 6088.

[64] Santra, S.; Bagdi, A. K.; Majee, A.; Hajra, A. RSC Adv. 2013, 3, 24931.

[65] Farrokhi, A.; Ghodrati, K.; Yavari, I. Catal. Commun. 2015, 63, 41.

[66] Maleki, A.; Aghaei, M.; Ghamari, N. Chem. Lett. 2015, 44, 259.

[67] Zhang, J.; Ren, D. C.; Ma, Y. M.; Wang, W. T.; Wu, H. Tetrahedron 2014, 70, 5274.

[68] Zhang, J.; Zhao, J. W.; Wang, L. P.; Liu, J.; Ren, D. C.; Ma, Y. M. Tetrahedron 2016, 72, 936.

[69] Zhang, J.; Liu, J.; Ma, Y. M.; Ren, D. C.; Cheng, P.; Zhao, J. W.; Zhang, F.; Yao, Y. Bioorg. Med. Chem. Lett. 2016, 26, 2273.

[70] Zhang, J.; Cheng, P.; Ma, Y. M.; Liu, J.; Miao, Z.; Fan, C. Chin. J. Org. Chem. 2016, 36, 1368 (in Chinese).

(张金, 程佩, 马养民, 刘佳, 苗智, 范超, 有机化学, 2016, 36, 1368.)

[71] Zhang, J.; Liu, J.; Ma, Y. M.; Yang, X. F.; Cheng, P.; Fan, C.; Lu, P. Chem. J. Chin. Univ. 2016, 37, 1629 (in Chinese). (张金, 刘佳, 马养民, 杨秀芳, 程佩, 范超, 卢萍, 高等学校化 学学报, 2016, 37, 1629.)

(Zhao, X.) 